\title{
Bronchoalveolar Biopsy Specimen
}

National Cancer Institute

\section{Source}

National Cancer Institute. Bronchoalveolar Biopsy Specimen. NCI Thesaurus. Code C155830.

T issue removed from the bronchi and alveoli for microscopic examination. 